\title{
Influences of dispersal and local environmental factors on stream macroinvertebrate communities in Qinjiang River, Guangxi, China
}

\author{
Yong Zhang ${ }^{1,2}$, Jie Zhang ${ }^{1}$, Lizhu Wang ${ }^{3}$, Dongqi $\mathrm{Lu}^{1}$, Desuo $\mathrm{Cai}^{4}{ }^{4}$, Beixin Wang ${ }^{1, *}$ \\ ${ }^{1}$ Department of Entomology, Nanjing Agricultural University, Nanjing 210095, PR China \\ ${ }^{2}$ Tianjin Nankai High Scool, Tianjin 300100, PR China \\ ${ }^{3}$ International Joint Commission, Great Lakes Office, PO Box 32869, Detroit, Michigan 48232, USA \\ ${ }^{4}$ College of Civil Engineering and Architecture, Guangxi University, Nanning 530004, PR China
}

\begin{abstract}
Identifying the underlying mechanisms that explain the spatial variation of stream macroinvertebrate assemblages is crucial for the protection of species diversity. Consequently, questions regarding how much variance in macroinvertebrate community structure is related to spatial dispersal and local environmental factors, and which environmental variables are the key drivers have broad research and management implications. Based on data from 22 stream sites within the Qinjiang River watershed, Guangxi, China, we examined the variation in macroinvertebrate community structure attributable to local environmental factors (i.e. stream physical habitat and water chemistry) vs. spatial dispersal factors (i.e. overland and watercourse spatial eigenvectors among sampling sites) using variation partitioning procedures. Overall, we found that stream macroinvertebrates are influenced both by local environmental factors and spatial dispersal factors. The most important environmental factors structuring macroinvertebrate assemblages were current velocity, dissolved oxygen, conductivity, total phosphorus, and physical habitat quality. Both overland and watercourse dispersal pathways had a similar influence on macroinvertebrate assemblages. These results demonstrate that stream macroinvertebrates within the studied landscape are constrained by local environmental conditions and dispersal factors, and hence comply with the niche-based species sorting hypothesis in the context of metacommunity ecology.
\end{abstract}

KEY WORDS: Macroinvertebrate $\cdot$ Spatial factors · Local environment $\cdot$ Stream $\cdot$ China

${ }^{*}$ Corresponding author: wangbeixin@njau.edu.cn

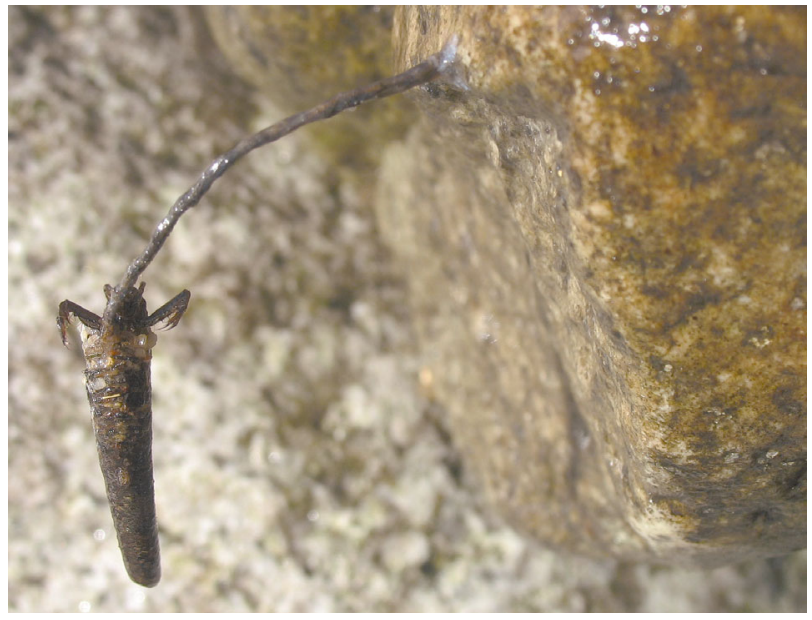

Predatory larvae of insects such as Limnocentropus sp., attached here to a rock by its silken peduncle, are important components of freshwater habitats.

Photo: Beixin Wang

\section{INTRODUCTION}

An important goal for community ecology is to identify major patterns of community structure, and to characterize and predict changes in those patterns in relation to environmental gradients (Soininen et al. 2004). It is being increasingly recognized that community structure is determined both by local processes (e.g. local environment) and regional settings (e.g. dispersal and migration) (Cornell \& Lawton 1992, Vanschoenwinkel et al. 2007). However, most early community studies assumed that local commu-

() The authors 2014. Open Access under Creative Commons by Attribution Licence. Use, distribution and reproduction are unrestricted. Authors and original publication must be credited. 
nities were closed and isolated, and focused on local processes - such as competition, predation, and local environmental heterogeneity-despite the fact that regional settings can strongly influence these processes when local communities are connected to each other. A recently developed theory defines 'metacommunity' as a set of local communities that are linked by dispersal of multiple potentially interacting species with a few key processes pertaining to patch dynamics, species sorting, mass effect, and neutrality (Hanski \& Gilpin 1997, Leibold et al. 2004). This concept has successfully explained the distribution patterns of aquatic organisms and the drivers determining such patterns (Thompson \& Townsend 2006, Heino \& Mykrä 2008, Jacobson \& Peres-Neto 2010, Heino 2013). Although much is known about how these processes affect freshwater community structure, such impacts are regionally specific (Beisner et al. 2006).

Previous findings on the relative importance of local versus regional processes in shaping aquatic organism composition are inconsistent. Heino \& Mykrä (2008) found that there were no spatial location effects on stream insect assemblages, since these assemblages were not strongly dispersal-limited across the study drainage system. Astorga et al. (2011) showed that freshwater macroinvertebrate species richness was structured both by local variables and factors at broad spatial scales, showing the presence of spatially-structured environmental variation. Vanschoenwinkel et al. (2007) reported that local abiotic factors were dominant over spatial factors in explaining invertebrate community structure, and local and regional factors acted almost independently. In contrast, Beisner et al. (2006) found that motile species community composition (e.g. lake crustacean zooplankton and fish) were better predicted by spatial factors than by local environmental factors. In general, it is thought that the importance of local environmental factors in explaining macroinvertebrate assemblage structure increases as spatial dispersal distance decreases and the importance of spatial dispersal factors decreases (Mykrä et al. 2007).

Stream segments within a river network are considered a good ecological setting for studying community structure in a metacommunity context (Heino \& Mykrä 2008). Stream macroinvertebrates are of high diversity in most river systems (Rosenberg \& Resh 1993), and their distribution is influenced by environmental variables and processes at multiple spatial scales. Currently, studies of stream macroinvertebrate community patterns and their relationships with spatial and environmental variables in a metacommunity context are rare (but see Cottenie 2005, Thompson \& Townsend 2006, Heino \& Mykrä 2008). To date, and to our knowledge, no study has investigated the relative roles of local environmental conditions vs. spatial dispersal factors in stream macroinvertebrate community structure in stream systems in China.

In this study, we investigated the influences of spatial factors as well as environmental variables on macroinvertebrate community structures in a metacommunity context in the Qinjiang River watershed, Guangxi Zhuang Autonomous Region, China. We hypothesized that the pattern of macroinvertebrate community composition in a minimally humandisturbed landscape would generally comply with a niche-based species sorting hypothesis. Our specific objectives were to (1) quantify the amount of spatially structured variation in stream macroinvertebrate communities, (2) examine the proportion of variation in macroinvertebrate community structure explained by local environmental variables and by spatial factors, both jointly and separately, and (3) identify the major environmental variables that determine macroinvertebrate distribution patterns in the Qinjiang River watershed.

\section{MATERIALS AND METHODS}

\section{Study area}

The Qinjiang River watershed is located between $21^{\circ} 52^{\prime}-22^{\circ} 34^{\prime} \mathrm{N}$ and $108^{\circ} 34^{\prime}-109^{\circ} 30^{\prime} \mathrm{E}$, with an area of $2391 \mathrm{~km}^{2}$ in south-western Guangxi province, China (Fig. 1). The watershed is $195 \mathrm{~km}$ in length with a mean slope of $0.32 \%$. The study area is characterized by a tropical oceanic monsoon climate with a mean annual temperature of $\sim 20^{\circ} \mathrm{C}$. Annual precipitation is $\sim 1600 \mathrm{~mm}$, occurring mostly between May and September. Although the Qinjiang River region has been modified by urban, agricultural, and industrial activities during the last several decades, the dominant land cover in the study area is forest.

\section{Macroinvertebrate sampling}

Based on accessibility, land-use gradient, and spatial distribution, 22 stream sites from the upper to the lower reaches of Qinjiang River were sampled in January 2010 (Fig. 1). Ten macroinvertebrate samples were collected from all available habitat types in a $100 \mathrm{~m}$ section of each stream using a $30 \mathrm{~cm}$ wide 


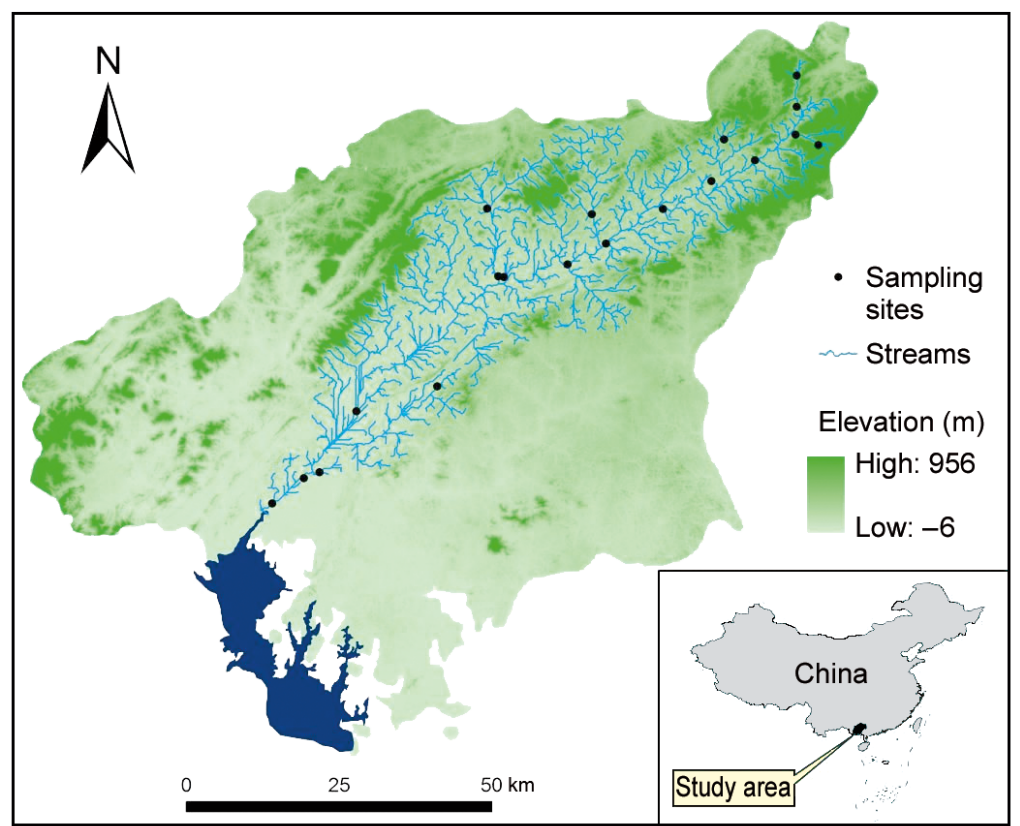

Fig. 1. Location of Qinjiang River Basin and the spatial distribution of sampling sites

D-frame net with $250 \mu \mathrm{m}$ mesh size (Barbour et al. 1999). The 10 samples, each from an area of $0.15 \mathrm{~m}^{2}$, were combined into a composite sample (total area $=1.5 \mathrm{~m}^{2}$ ). Samples were processed in the field by washing in buckets to remove large organic debris and rocks, followed by repeated elutriation of the sample to remove macroinvertebrates from remnant debris. The D-net was visually inspected to ensure macroinvertebrates adhering to the net were transferred to the composite sample. All materials were placed into a plastic container and preserved in $10 \%$ buffered formalin. In the laboratory, all organisms in the sample were counted and identified to genus or to the lowest taxonomic level possible according to Morse et al. (1994).

\section{Local environmental variables}

At each site, water temperature $(T), \mathrm{pH}$, conductivity, mean wetted width (WW), current velocity $(V)$, dissolved oxygen (DO) concentrations, and the dominant substrate were measured using the methods described by earlier studies (Wu et al. 2010, Wang et al. 2012). Before collecting macroinvertebrate samples, water samples were collected, preserved, and analyzed according to the standard methods for the analysis of water and wastewater (EPBC 2002). The analyzed environmental variables from the water samples included concentrations of total nitrogen
(TN), ammonia nitrogen $\left(\mathrm{NH}_{4}-\mathrm{N}\right)$, total phosphorus (TP), and chemical oxygen demand (COD).

Semi-quantitative habitat variables were measured or visually assessed using the methods of Barbour et al. (1999) with minor modifications. At each stream reach, 8 habitat characteristic measures were calculated (see the Supplement at www.int-res.com/articles/suppl/b020 p185_supp.pdf). These measures included velocity/depth regime (a combination measurement of current and water depth characteristics in 4 categories), channel flow status, channel alteration, frequency of riffles (a ratio of distance between riffles and wetted channel width), channel sinuosity, bank stability, riparian vegetative zone width, and substrate composition. Each measure was rated with a score from 0 (the least diversified condition) to 20 (the most diversified condition). The final habitat quality index (HQI) score was the sum of scores of the 8 measures, with a maximum score of 160. See Lu et al. (2013) for more details on the calculation and rating of the 8 habitat characteristic measures.

\section{Spatial factors}

The majority of macroinvertebrates can disperse through downstream flows, and some life stages can also move overland. To assess the influence of these 2 different mechanisms of dispersal on macroinvertebrate community structure, we measured the straight overland distances from one sampling site to the other 21 sampling sites (site-to-site pairs) based on the 1:100000 scale National Hydrographic Dataset, using geographical coordinates of the sampling sites with ARC/INFO 9.3.1 software. We also measured the stream watercourse distances from one sampling site to the other sampling sites that had upstreamdownstream flow relationships using the same dataset and software as described above.

\section{Data analysis}

We constructed and analyzed spatial matrices for watercourse distance and overland distance between each sampling site pair separately. For overland distances between sampling sites, we conducted princi- 
pal coordinates of neighbor matrices (PCNM) analysis and retained the principal coordinates with positive eigenvalues as spatial factors for subsequent analyses (Borcard \& Legendre 2002, Borcard et al. 2004, Dray et al. 2006). For watercourse distances between sampling sites, we used asymmetric eigenvector map (AEM) procedures (Blanchet et al. 2008a, 2011, Borcard et al. 2011). We retrained all the matrices at this step, and the number of variables within each matrix was reduced by separate forward selection of variables as described below. We used PCNM for overland spatial eigenvectors and AEM for watercourse spatial eigenvectors because PCNM analysis is well-suited to model spatial structures on a plane, while AEM works better for modeling directional spatial processes such as dominant wind and current directions (Blanchet et al. 2008a). Both PCNM and AEM analyses were conducted in the R environment (Oksanen et al. 2011).

We conducted forward selection procedures to reduce and select the spatial eigenvectors and local environmental variables separately for subsequent analyses using the function 'forward.sel' in the 'packfor' package (Dray et al. 2011). In this process, macroinvertebrate relative abundance was used as a response variable and the spatial eigenvectors (i.e. PCNMs and AEMs) and local environmental variables were used as independent variables. Prior to the forward selection procedures, we performed a global test (i.e. a redundancy analysis including all the variables in a variable group) to evaluate the effects of spatial eigenvectors and local environmental variables on the response variables. Significant variables were identified by forward selection and were included in the further partitioning procedures (Blanchet et al. 2008b). For significant spatial eigenvectors, we used the function 'ordisurf' for detecting the scale and shape of the influence of these eigenvectors on the macroinvertebrate community.

Our analyses included 3 main components. We first evaluated the relative influences of the AEM and PCNM eigenvectors in determining macroinvertebrate relative abundance using redundancy analysis (RDA)-based variation partitioning procedures. We then identified the influence of key local environmental variables on macroinvertebrate relative abundance using RDA. A preliminary analysis indicated that RDA is more suitable for our analysis because a detrended correspon- dence analysis on macroinvertebrate relative abundance had gradient lengths $<3$ standard deviations for axes 1 and 2 (ter Braak \& Prentice 2004). Finally, we quantified the proportion of the variation in macroinvertebrate relative abundance explained by local environmental variables and spatial eigenvectors. We used RDA-based variation partitioning procedures to calculate the variance of macroinvertebrate assemblages explained by spatial factors, by local environmental variables alone, by both spatial factors and local environmental variables, and the unexplained fractions of the total variation. In this procedure, we used the improved version of the RDA-based partitioning procedure with a double stopping criterion to minimize the risk of including too many predictors (Blanchet et al. 2008b). We used adjusted $\mathrm{R}^{2}$ values to minimize the influences of the number of sampling sites and number of explanatory variables (Peres-Neto et al. 2006), and report adjusted $R^{2}$ values $\left(R^{2}{ }_{a}\right)$ throughout. The significance of the fractions explained by the spatial eigenvectors (i.e. AEMs and PCNMs) and local environmental variables were tested using 999 permutations at a significance level of 0.05 (Legendre \& Legendre 1998, Peres-Neto et al. 2006). All statistical analyses were carried out in the R environment using the 'vegan' package (Oksanen et al. 2011).

\section{RESULTS}

Our sampling sites consisted of a wide range of local environmental variables (Table 1). Values for WW ranged from $<2$ to $51 \mathrm{~m}, V$ ranged from $0.1 \mathrm{~s}^{-1}$ to $0.6 \mathrm{~m} \mathrm{~s}^{-1}$, and $T$ ranged from 14 to $21^{\circ} \mathrm{C}$ with a mean of $18^{\circ} \mathrm{C}$. TN and TP showed a clear upstreamdownstream pattern along the Qinjiang River, with a tendency to increase from the upper section sites to

Table 1. Physical habitat variables and water quality characteristics for the sampling sites; all factors were averaged

\begin{tabular}{|lcc|}
\hline Variable & Abbreviation & Mean \pm SE (Range) \\
\hline Wetted width $(\mathrm{m})$ & $\mathrm{WW}$ & $15.9 \pm 5.7(1.5-51)$ \\
Flow velocity $\left(\mathrm{m} \mathrm{s}^{-1}\right)$ & $V$ & $0.3 \pm 0.0(0.1-0.6)$ \\
Temperature $\left({ }^{\circ} \mathrm{C}\right)$ & $T$ & $17.5 \pm 0.4(14.4-21)$ \\
Dissolved oxygen $\left(\mathrm{mg} \mathrm{l}^{-1}\right)$ & $\mathrm{DO}$ & $7.5 \pm 0.5(4.1-10.9)$ \\
Stream water $\mathrm{pH}$ & $\mathrm{pH}$ & $8.5 \pm 0.2(7.5-10.5)$ \\
Conductivity $\left(\mu \mathrm{Cm}^{-1}\right)$ & $\mathrm{Conductivity}$ & $54.3 \pm 29.5(31-260)$ \\
Total nitrogen $\left(\mathrm{mg} \mathrm{l}^{-1}\right.$ & $\mathrm{TN}$ & $1.8 \pm 0.3(0.2-4.9)$ \\
Total phosphorus $\left(\mathrm{mg} \mathrm{l}^{-1}\right)$ & $\mathrm{TP}$ & $0.2 \pm 0.1(0.0-0.8)$ \\
NH $_{4}$ - $\mathrm{N}$ concentration $\left(\mathrm{mg} \mathrm{l}^{-1}\right)$ & $\mathrm{NH}_{4}$-N & $0.7 \pm 0.2(0.1-3.3)$ \\
${\text { Chemical oxygen demand }\left(\mathrm{mg} \mathrm{l}^{-1}\right)}^{\mathrm{COD}}$ & $5.0 \pm 1.1(1.7-20.4)$ \\
\hline
\end{tabular}


the middle and lower section sites. The deposition of sediment was also observed in the middle and lower regions of Qinjiang River Basin. The predominant substrate was sand, followed by silt, gravel, and cobble.

A total of 59 taxa of 37 families were observed. Branchiura sowerbyi, Cipangopaludina chinensis, Baetis sp., and Tanytarsini sp. were dominant, occurring in more than $50 \%$ of the sampling sites. Most upstream sites were dominated by Ephemeroptera, Trichoptera, and Coleoptera, while downstream sites were dominated by Tubificidae, Herpodellidae, and some Mollusca.

In total, 21 AEM eigenvectors and 14 PCNM eigenvectors with positive values were generated. For these 35 spatial eigenvectors and 11 local environmental variables, 15 variables were retained for macroinvertebrate datasets by the forward selection procedures, including 5 local environmental variables (i.e. DO, TP, V, conductivity and HQI), 4 overland spatial eigenvectors (i.e. PCNM5, PCNM7, PCNM13, PCNM14), and 6 watercourse spatial eigen-
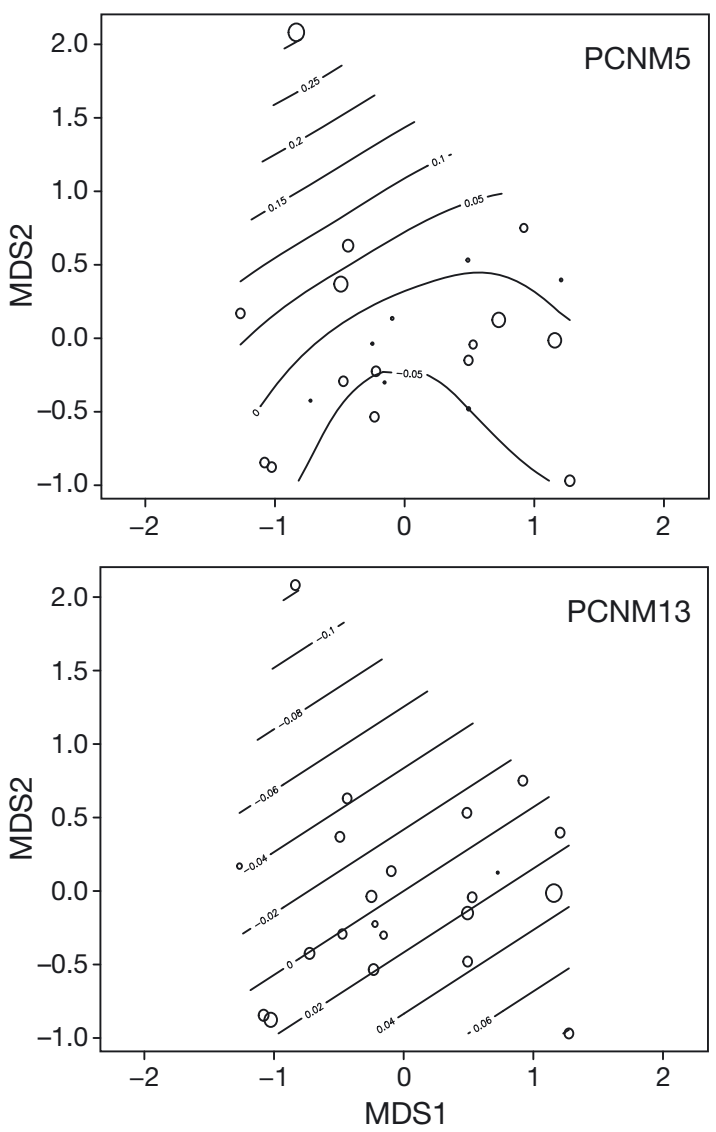

vectors (i.e. AEM19, AEM3, AEM18, AEM6, AEM1, AEM9) (Table 1, Fig. 2). Both local environmental variables and spatial factors were significant in explaining macroinvertebrate composition. When only AEM eigenvectors and PCNM eigenvectors were considered, AEM eigenvectors alone explained $21.6 \%$ ( $\mathrm{p}<0.001$ ) and PCNM eigenvectors alone explained $15.1 \%(p<0.001)$ of the total variation in macroinvertebrate composition. The variation explained by these 2 types of spatial eigenvectors jointly was $7.2 \%$ (Fig. 3). When AEM eigenvectors and local environmental variables were considered together, AEM eigenvectors explained $7.5 \%$ and the local environmental variables explained $14.6 \%$ of the total variation in macroinvertebrate composition (Fig. 3). When PCNM eigenvectors and local environmental variables were considered together, PCNM eigenvectors explained $12.4 \%$ and the local environmental variables explained $18.5 \%$ of the total variation in macroinvertebrate composition (Fig. 3).
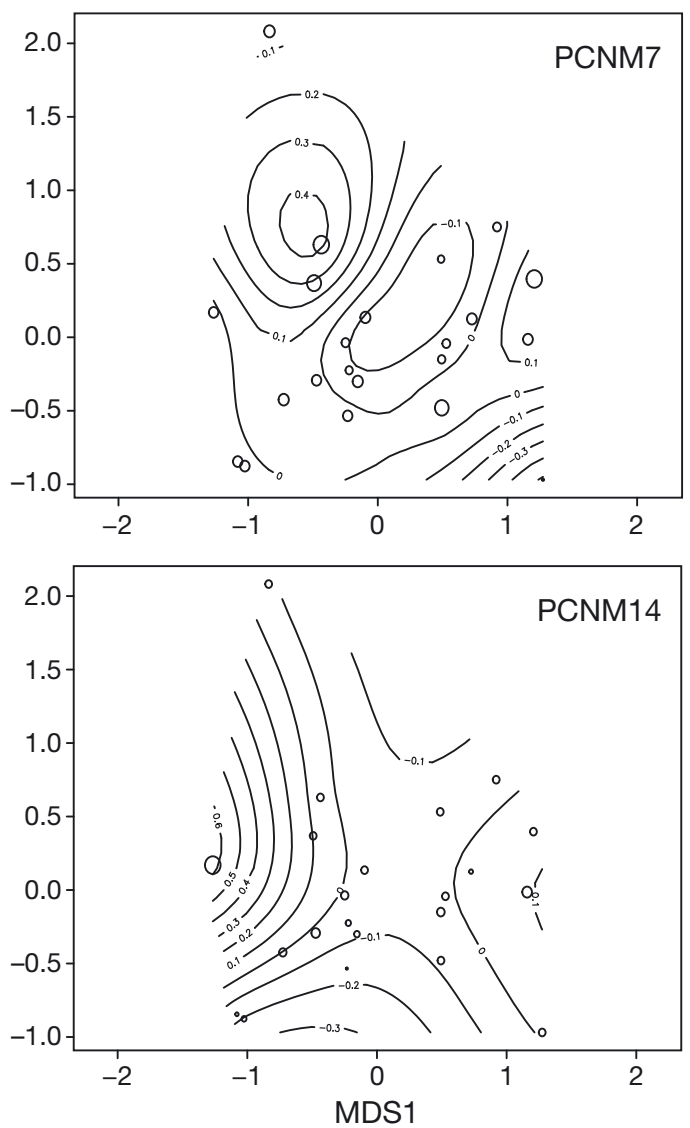

Fig. 2. Ordination diagrams for the significant principal coordinates of neighbour (PCNM) vectors and asymmetric eigenvector maps (AEM) vectors at catchment scale in the Qinjiang River region, with fitted smooth surfaces using thinplate splines in general additive models: PCNM5, PCNM7, PCNM13, PCNM14; and AEM19, AEM3, AEM18, AEM6, AEM1, and AEM9. Vectors appeared in order of importance. Bubbles indicate the positions of sampling sites. The size of the bubbles is associated with eigenvector values, from negative (small bubbles) to positive values (larger bubbles). Splines show the actual values for each vector 

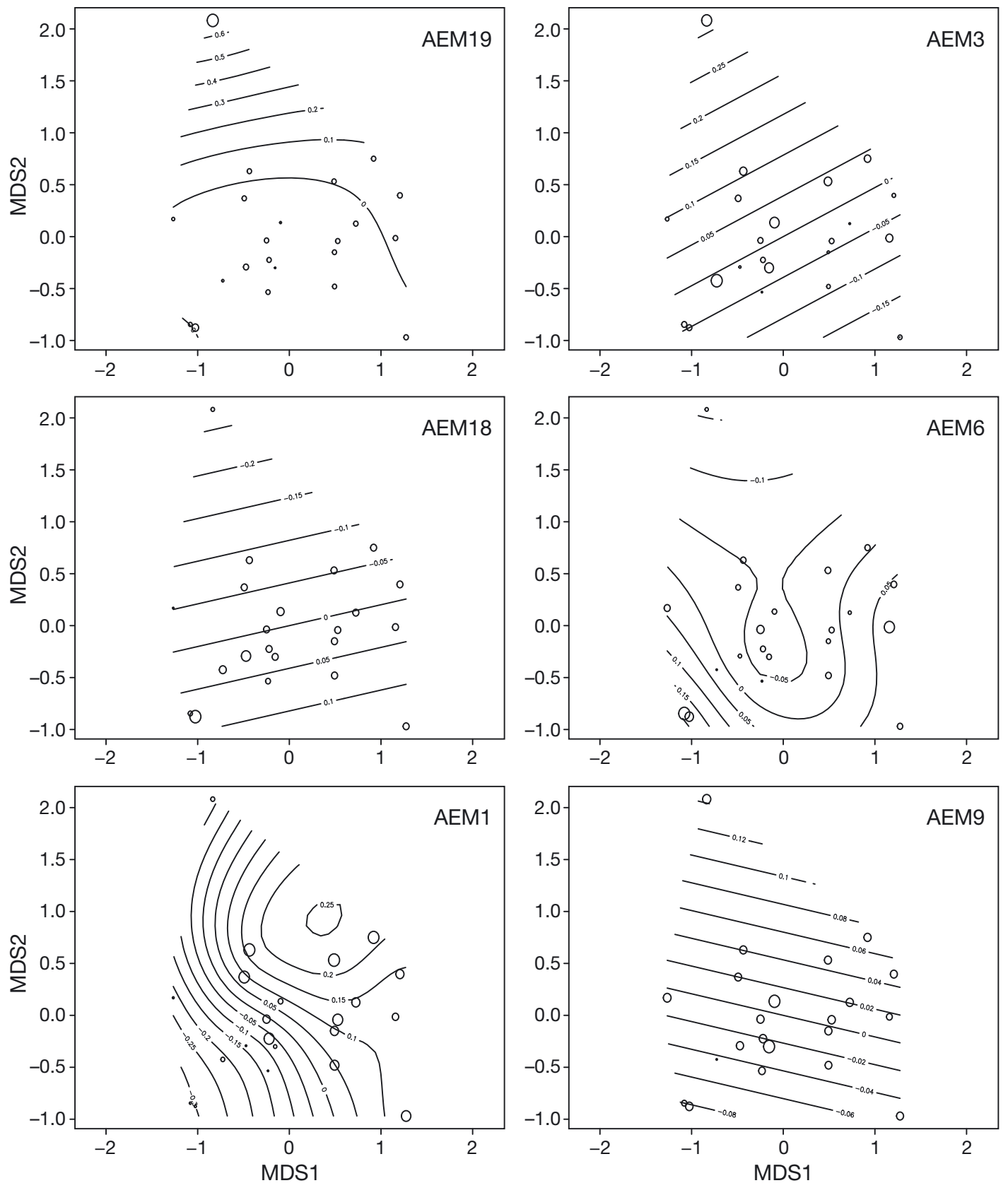

Fig. 2 (continued)

All local environmental variables (i.e. $V$, DO, conductivity, TP and HQI) identified by the forward selection procedure were significantly correlated with macroinvertebrate composition (Fig. 4). When only local environmental variables were considered, they explained $31.8 \%$ of macroinvertebrate composition; axis 1 explained $21 \%$ of the composition. This axis was strongly influenced by TP and HQI. According to the bi-plot of macroinvertebrate community composition and local environmental variables (Fig. 4), Ecnomus sp., Baetiella sp., Caenis sp., Ephemera sp., and Ephemerella sp. were positively correlated with HQI and negatively correlated with TP. In contrast, Epophthalmia sp., Simuliidae sp., Scirtes sp., and Baetis sp. had a positive relationship with DO and $V$, and a negative relationship with conductivity (Fig. 4).

\section{DISCUSSION}

Our results indicate that stream macroinvertebrate compositions are clearly influenced by both spatial 


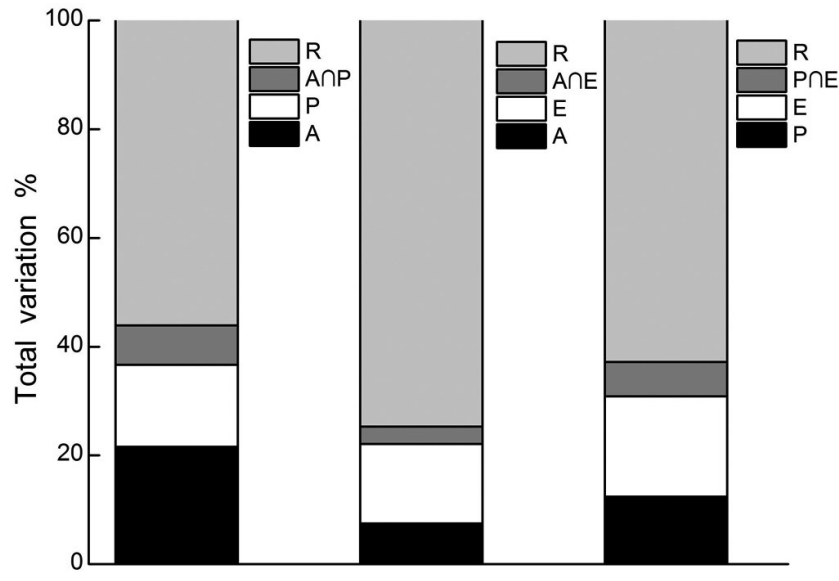

Fig. 3. Results of the redundancy analysis (RDA)-based variation partitioning procedure in the macroinvertebrate community for analyses using spatial eigenvectors between sampling sites and local environmental variables. From left to right, $\mathrm{R}$ indicates residual (i.e. unexplained) variability, A indicates the fraction of variance explained by AEM eigenvectors, $\mathrm{P}$ indicates the fractions of variance explained by PCNM eigenvectors, $\mathrm{E}$ indicates the fractions of variance explained by pure local environment, and $\mathrm{A} \cap \mathrm{P}, \mathrm{A} \cap \mathrm{E}$, and $\mathrm{P} \cap \mathrm{E}$ show the fractions of variation commonly explained by spatial eigenvectors and local environmental variables factors (i.e. AEM and PCNM eigenvectors) and local environmental variables in the Qinjiang River system. Our results also indicate that local environmental variables have a stronger influence on stream macroinvertebrate compositions than spatial factors, measured both by overland and watercourse spatial eigenvectors.

It has been increasingly recognized that biological community structure is largely determined by both local and regional processes (Cornell \& Lawton 1992, Cottenie 2005, Vanschoenwinkel et al. 2007), but the relative importance of these 2 types of processes are still in debate (Rajaniemi et al. 2006). In their study of zooplankton assemblages in ponds, Cottenie et al. (2003) found that both the local environmental variables and spatial factors independently related to zooplankton composition. Our study found that the fraction of variance explained by both spatial and environmental variables were much smaller (3.2 and $6.3 \%$, AEMs and PCNMs, respectively) than by spatial measures alone (7.5 and $12.4 \%$ ) or environmental variables alone (14.6 and $18.5 \%$ ). Our results are similar to those of Cottenie et al. (2003), in that spatial
Fig. 4. Redundancy analysis ordination of local environmental variables and macroinvertebrate community relative abundance for all sampling sites. All vectors are significant $(\mathrm{p}<$ 0.05; 999 Monte Carlo permutation tests). Crosses $=$ upper section sites, triangles = middle section sites, and squares = lower section sites. See Table 1 and the Supplement (www.intres.com/articles/suppl/b020 p185_supp.pdf) for variable explanations




configuration was not very strongly correlated with measured local environmental variables. In another study of stream macroinvertebrate community structure in relation to spatial and environmental factors, Heino \& Mykrä (2008) reported a different pattern, in which local environmental variables were weakly associated with stream organism assemblage structure, and sampling site spatial configuration had no effect. The difference between the study of Heino \& Mykrä (2008) and ours is likely a result of different environmental gradients and organism groups. In the Heino \& Mykrä (2008) study, although the sampled streams spanned relatively large physical gradients, the studied headwater streams did not incorporate strong water chemistry gradients, resulting in weak assemblage-environment relationships (Heino \& Mykrä 2008). Although our study was at a similar spatial scale (about $2 \times 10^{3} \mathrm{~km}^{2}$ ), our sampling sites spanned a wide environmental gradient. Additionally, Heino \& Mykrä (2008) analyzed mayflies (Ephemeroptera), stoneflies (Plecoptera), caddisflies (Trichoptera), and non-biting midges (Diptera: Chironomidae) in each year separately. Our study analyzed the entire assemblage, including Mollusca and Oligochaeta. There are a few other studies on freshwater systems that have taken into account both local and regional processes. For example, Johnson et al. (2007) found that 4 groups of organisms (macrophytes, diatoms, invertebrates, and fish) responded similarly to different levels of spatial scale. Beisner et al. (2006) estimated the relative role of local environmental and spatial processes in structuring lake communities from bacteria to fish (bacteria, phytoplankton, zooplankton, and fish), and found that crustacean zooplankton and fish were better predicted by spatial factors than by local environmental variables. However, they only reported the importance of incorporating spatial factors in their studies, but did not address the kind and shape of the spatial structure they studied.

Dispersal of stream macroinvertebrates has been recognized as an important phenomenon, with the potential to influence local community structure (Van de Meutter et al. 2006, Shurin et al. 2009). A variety of evidence supports the idea that both dispersal and local environmental conditions may structure macroinvertebrate communities (Briers \& Biggs 2005, Thompson \& Townsend 2006, Jacobson \& Peres-Neto 2010, Heino et al. 2012). Our findings are consistent with the idea that both spatial configuration and local environmental variables are influential factors in determining stream macroinvertebrate structures. Our results imply that overland spatial eigenvectors act on stream macroinvertebrate communities at small and intermediate scales (e.g. PCNM13 and PCNM14 represent small-scale variation, whereas PCNM5 and PCNM7 represent intermediate-scale variation). However, for watercourse spatial eigenvectors, the small-scale (i.e. AEM18 and AEM19), intermediate-scale (i.e. AEM6 and AEM9), and large-scale (i.e. AEM1 and AEM3) factors are strongly related to stream macroinvertebrate community structure. The study of dispersal pathways of stream macroinvertebrates has been considered difficult (see review by Bilton et al. 2001), partially because some species disperse through watercourses while others can also disperse overland (Bilton et al. 2001, Landeiro et al. 2011). Our study implies that both overland and watercourse dispersal were important in Qinjiang River. Our results also indicate that both watercourse and overland dispersal is important to stream macroinvertebrate distribution, implying that some macroinvertebrate species can disperse through either overland or watercourse, or both. In order to further identify which species in particular disperse via which mechanism, a combined analysis including local environmental and both types of spatial measures would have to be performed. Unfortunately, the total number of predictors (15 total: 5 environmental [DO, TP, $V$, conductivity, and HQI] + 4 overland [PCNM5, PCNM7, PCNM13, and PCNM14] + 6 watercourse eigenvectors [AEM19, AEM3, AEM18, AEM6, AEM1, and AEM9]) is too high, and such a combined analysis would lead to a biased estimate of variance explanation, even under adjustment for the number of observations. However, we could still estimate the relative importance of 3 types of factors. Local environmental variables had the most important role (about 51.1 to $59.5 \%$ of the total explained variations) in shaping upstream to downstream macroinvertebrates community structure in Qinjiang River, followed by PCNM (34.6\%) and AEM (30.6\%). In addition, we can also examine the relationships between significant spatial factors and macroinvertebrate assemblages by overlaying the key spatial eigenvectors onto the ordination plot of macroinvertebrate species (Fig. 2).

We found that stream macroinvertebrate composition was significantly related to local environmental variables, such as $V$, DO, conductivity, TP, and HQI. Although a direct comparison between our RDA results and results obtained through canonical correlation analysis (CCA) is not plausible since the variation is not defined in the same way, existing results from the literature, based on CCA among environmental variables from different spatial scales, still 
partly support our findings (Death \& Joy 2004, Johnson et al. 2007, Wang et al. 2012). For example, Sandin \& Johnson (2004), using a variance partitioning approach (pCCA), showed that local physical (water velocity) and local chemical (e.g. K concentration) variables explained the largest part of the among-site variability of macroinvertebrate communities of boreal streams. In a similar subtropical monsoon region, Wu et al. (2010) identified that ammonia nitrogen, canopy, water conductivity, and habitat complexity were significant predictors of stream macroinvertebrate communities. Although our study includes most environmental variables previously known to structure stream macroinvertebrate assemblages, including physical habitat characteristics and water chemistry (Heino et al. 2003, Sandin \& Johnson 2004, Heino \& Mykrä 2008, Wu et al. 2010), missing factors such as watershed land cover and geology may have resulted in the relatively low explained percentages of variance for macroinvertebrate composition. Additionally, our study sampled each site only once, and did not take temporal variation into account, so the present study represents a snapshot of stream macroinvertebrate community structure, and further investigations taking temporal variation into account are needed.

Overall, our study from a relatively undisturbed watershed demonstrates that both local environmental variables and overland and watercourse spatial eigenvectors are important factors determining the relative abundance of stream macroinvertebrate communities for the Qinjiang River system in China. These results are consistent with the concept developed for stream fish communities in North America (Poff 1997), in that local environmental characteristics are the main factors determining biological assemblage structure at individual stream reach scale, while species occurrence is largely determined by the availability of a regional source of species, which disperse overland and through watercourses at finer scales. Species in the regional pool must pass different spatial scale filters (such as the spatial factors we measured) in order to be included in the local biological communities. Our findings are also consistent with the metacommunity concept that is defined as a set of local communities linked by dispersal of multiple, potentially interacting species, with a few key processes in terms of patch dynamics, species sorting, mass effect, and neutrality (Hanski \& Gilpin 1997, Leibold et al. 2004). Such findings have important implications for biomonitoring and bioassessment, as well as biodiversity conservation. When identifying key factors determining biological assemblages for ecosystem management, we not only need to include local environmental variables, but also must include spatial factors - which have largely been ignored in the literature. When conserving local biodiversity within the scope of landscape anthropogenic development and climate changes, we not only need to consider preventing degradation of local environmental factors, but also identify and protect regional species pools that could improve local biodiversity through dispersal when local community species are extirpated by extreme events or climate change.

Acknowledgements. This research was supported by the National Science Foundation of China (Project No. 40971280, 41271525) and Department of Water Resources of Guangxi Zhuang Autonomous Region. Y. Cao, K. Chen, S. Liu and D. Liu assisted with the field work. We thank Professor L. Yang for her help in organism identification. Three anonymous reviewers provided constructive comments and suggestions that substantially improved the manuscript.

\section{LITERATURE CITED}

Astorga A, Heino J, Luoto M, Muotka T (2011) Freshwater biodiversity at regional extent: determinants of macroinvertebrate taxonomic richness in headwater streams. Ecography 34:705-713

Barbour MT, Gerritsen J, Snyder BD, Stribling JB (1999) Rapid bioassessment protocols for use in streams and wadeable rivers: periphyton, benthic macroinvertebrates, and fish: 2nd edn. US Environmental Protection Agency, Washington, DC

Beisner BE, Peres-Neto PR, Lindström ES, Barnett A, Longhi ML (2006) The role of environmental and spatial processes in structuring lake communities from bacteria to fish. Ecology 87:2985-2991

> Bilton DT, Freeland JR, Okamura B (2001) Dispersal in freshwater invertebrates. Annu Rev Ecol Syst 32:159-181

> Blanchet FG, Legendre P, Borcard D (2008a) Modelling directional spatial processes in ecological data. Ecol Modell 215:325-336

> Blanchet FG, Legendre P, Borcard D (2008b) Forward selection of explanatory variables. Ecology 89:2623-2632

> Blanchet FG, Legendre P, Maranger R, Monti D, Pepin P (2011) Modelling the effect of directional spatial ecological processes at different scales. Oecologia 166:357-368

Borcard D, Legendre P (2002) All-scale spatial analysis of ecological data by means of principal coordinates of neighbour matrices. Ecol Model 153:51-68

Borcard D, Legendre P, Avois-Jacquet C, Tuomisto H (2004) Dissecting the spatial structure of ecological data at multiple scales. Ecology 85:1826-1832

Borcard D, Gillet F, Legendre P (2011) Numerical ecology with R. Springer, New York, NY

Briers RA, Biggs J (2005) Spatial patterns in pond invertebrate communities: separating environmental and distance effects. Aquat Conserv 15:549-557

Cornell HV, Lawton JH (1992) Species interactions, local and regional processes, and limits to the richness of ecological communities: a theoretical perspective. J Anim Ecol 61:1-12 
Cottenie K (2005) Integrating environmental and spatial processes in ecological community dynamics. Ecol Lett 8: 1175-1182

Cottenie K, Michels E, Nuytten N, De Meester L (2003) Zooplankton structure: regional vs. local processes in highly interconnected ponds. Ecology 84:991-1000

> Death RG, Joy MK (2004) Invertebrate community structure in streams of the Manawatu-Wanganui region, New Zealand: the roles of catchment versus reach scale influences. Freshw Biol 49:982-997

Dray S, Legendre P, Peres-Neto PR (2006) Spatial modelling: a comprehensive framework for principal coordinate analysis of neighbour matrices (PCNM). Ecol Model 196: 483-493

Dray S, Legendre P, Blanchet G (2011) packfor: forward selection with permutation. $\mathrm{R}$ package version $0.0-8 / \mathrm{r} 100$. http://R-Forge.R-project.org/projects/sedar/

EPBC (Environmental Protection Bureau the People's Republic of China) (2002) Standard methods for the monitoring and analysis on water and wastewater, $4^{\text {th }}$ edn. Chinese Environmental Science Press, Beijing

Hanski IA, Gilpin ME (eds) (1997) Metapopulation biology: ecology, genetics, and evolution. Academic Press, San Diego, CA

$>$ Heino J (2013) The importance of metacommunity ecology for environmental assessment research in the freshwater realm. Biol Rev Camb Philos Soc 88:166-178

> Heino J, Mykrä H (2008) Control of stream insect assemblages: roles of spatial configuration and local environmental factors. Ecol Entomol 33:614-622

> Heino J, Muotka T, Mykrä H, Paavola R, Hamalainen H, Koskenniemi E (2003) Defining macroinvertebrate assemblage types of headwater streams: implications for bioassessment and conservation. Ecol Appl 13:842-852

Heino J, Grönroos M, Soininen J, Virtanen R, Muotka T (2012) Context dependency and metacommunity structuring in boreal headwater streams. Oikos 121:537-544

> Jacobson B, Peres-Neto PR (2010) Quantifying and disentangling dispersal in metacommunities: How close have we come? How far is there to go? Landscape Ecol 25: 495-507

> Johnson RK, Furse MT, Hering D, Sandin L (2007) Ecological relationships between stream communities and spatial scale: implications for designing catchment level monitoring programmes. Freshw Biol 52:939-958

> Landeiro V, Magnusson WE, Melo AS, Espirito-Santo H, Bini LM (2011) Spatial eigenfunction analyses in stream networks: Do watercourse and overland distances produce different results? Freshw Biol 56:1184-1192

Legendre P, Legendre L (1998) Numerical ecology, 2nd edn. Elsevier Science, Amsterdam

Leibold M, Holyoak M, Mouquet N, Amarasekare P and others (2004) The metacommunity concept: a framework for multi-scale community ecology. Ecol Lett 7:601-613

Lu DQ, Zhang Y, Cai DS, Liu SR, Chen YH, Wang BX (2013) Choice of macroinvertebrate metrics for constructing

Editorial responsibility: Christine Paetzold, Oldendorf/Luhe, Germany a benthic-index of biotic integrity based on the disturbance gradients in the Qinjiang River Basin. Environ Sci 34:137-144 (in Chinese with English Abstract)

Morse JC, Yang LF, Tian LX (1994) Aquatic insects of China useful for monitoring water quality. Hohai University Press, Nanjing

> Mykrä H, Heino J, Muotka T (2007) Scale-related patterns in the spatial and environmental components of stream macroinvertebrate assemblage variation. Glob Ecol Biogeogr 16:149-159

Oksanen J, Blanchet FG, Kindt R, Legendre P and others (2011) vegan: community ecology package. R package version 2.0-2. http://CRAN.R-project.org/package=vegan

> Peres-Neto PR, Legendre P, Dray S, Borcard D (2006) Variation partitioning of species data matrices: estimation and comparison of fractions. Ecology 87:2614-2625

$>$ Poff NL (1997) Landscape filters and species traits: towards mechanistic understanding and prediction in stream ecology. J N Am Benthol Soc 16:391-409

> Rajaniemi TK, Goldberg DE, Turkington R, Dyer AR (2006) Quantitative partitioning of regional and local processes shaping regional diversity patterns. Ecol Lett 9:121-128

Rosenberg DM, Resh VH (1993) Freshwater biomonitoring and benthic macroinvertebrates. Chapman \& Hall, New York, NY

Sandin L, Johnson RK (2004) Local, landscape and regional factors structuring benthic macroinvertebrate assemblages in Swedish streams. Landscape Ecol 19:501-514

Shurin JB, Cottenie K, Hillebrand H (2009) Spatial autocorrelation and dispersal limitation in freshwater organisms. Oecologia 159:151-159

Soininen J, Paavola R, Muotka T (2004) Benthic diatom communities in boreal streams: community structure in relation to environmental and spatial gradients. Ecography 27:330-342

ter Braak CJF, Prentice IC (2004) A theory of gradient analysis. Adv Ecol Res 34:236-278

> Thompson R, Townsend C (2006) A truce with neutral theory: local deterministic factors, species traits and dispersal limitation together determine patterns of diversity in stream invertebrates. J Anim Ecol 75:476-484

Van de Meutter F, Stoks R, De Meester L (2006) Lotic dispersal of lentic macroinvertebrates. Ecography 29:223-230

Vanschoenwinkel B, De Vries C, Seaman M, Brendonck L (2007) The role of metacommunity processes in shaping invertebrate rock pool communities along a dispersal gradient. Oikos 116:1255-1266

> Wang B, Liu D, Liu S, Zhang Y, Lu D, Wang LZ (2012) Impacts of urbanization on stream habitats and macroinvertebrate communities in the tributaries of Qiangtang River, China. Hydrobiologia 680:39-51

Wu DH, Yu HY, Wu HY, Zhou B, Wang BX (2010) Estimation of river nutrients thresholds based on benthic macroinvertebrate assemblages: a case study in the upper reaches of Xitiao Stream in Zhejiang, China. Chin J Appl Ecol 21:483-488 (in Chinese with English Abstract)

Submitted: August 17, 2013; Accepted: February 3, 2014

Proofs received from author(s): April 1, 2014 